$11-1-2012$

\title{
A Graphical Examination of Variable Deletion within the MEWMA Statistic
}

Jay R. Schaffer

University of Northern Colorado

Shawn VandenHul

University of Northern Colorado

Follow this and additional works at: http://digitalcommons.wayne.edu/jmasm

Part of the Applied Statistics Commons, Social and Behavioral Sciences Commons, and the Statistical Theory Commons

\section{Recommended Citation}

Schaffer, Jay R. and VandenHul, Shawn (2012) "A Graphical Examination of Variable Deletion within the MEWMA Statistic," Journal of Modern Applied Statistical Methods: Vol. 11 : Iss. 2 , Article 3.

DOI: $10.22237 /$ jmasm/1351742520

Available at: http://digitalcommons.wayne.edu/jmasm/vol11/iss2/3

This Regular Article is brought to you for free and open access by the Open Access Journals at DigitalCommons@WayneState. It has been accepted for inclusion in Journal of Modern Applied Statistical Methods by an authorized editor of DigitalCommons@WayneState. 


\title{
Regular Articles \\ A Graphical Examination of Variable Deletion within the MEWMA Statistic
}

\author{
Jay R. Schaffer Shawn VandenHul \\ University of Northern Colorado \\ Greeley, CO
}

A general procedure for identifying the variable(s) that contribute(s) to the signal of the multivariate extension of the exponentially weighted moving average (MEWMA) chart is presented. The procedure systematically removes one or two variables from the MEWMA statistic calculations. Percentages are calculated for correctly identifying various shifts.

Key words: Multivariate quality control, MEWMA, variable deletion.

\section{Introduction}

With modern computers, it is common to monitor several correlated quality characteristics simultaneously. Various types of multivariate control charts have been proposed to take advantage of the relationships among variables being monitored (Alt, 1984; Jackson, 1985; Wierda, 1994; Lowry and Montgomery, 1995; Mason, et al., 1997). Lowry, et al. (1992) proposed a multivariate extension of the exponentially weighted moving average (MEWMA) control chart. They demonstrated that the average run length (ARL) performance of the MEWMA is similar to that of the multivariate cumulative sum (MCUSUM) control charts discussed by Crosier (1988) and Pignatiello and Runger (1990) and is better than Hotelling's (1947) $\chi^{2}$ chart for detecting a shift in the mean vector of a multivariate normal distribution.

Woodall and Montgomery (1999) showed that, once an out-of-control signal is given by a multivariate chart, it may be difficult to identify the variable (or variables) that

Jay Schaffer is an Associate Professor of Statistics and is currently the chair of Applied Statistics and Research Methods. Email him at: jay.schaffer@unco.edu. Shawn VandenHul is a graduate of the Ph.D. program in Applied Statistics and Research Methods. contributed to the signal. Jackson $(1980,1991)$ proposed examining the Hotelling's $\mathrm{T}^{2}$ statistic (Jackson, 1985) using principle component analysis (PCA). Mason, et al. (1995) suggested decomposing Hotelling's $\mathrm{T}^{2}$ statistic by removing individual variables from its calculation. Woodall and Montgomery (1999) noted that additional work is needed on graphical methods for data visualization when interpreting signals from multivariate control charts.

This article presents a graphical approach to identify the source of a signal from the MEWMA control chart and examines the effects of systematically deleting a variable, or pairs of variables, from the calculations of the MEWMA statistic. The methodology is similar to examining the PRESS residuals (Allen, 1971) or DFBETAS (Belsley, et al., 1980) in regression analysis. Methodology used herein deletes variables in a multivariate process as opposed to deleting individual observations in a data set; in addition, the probability of correctly identifying the source using various simulations is estimated.

\section{MEWMA Chart}

Assume a sequence of independent observations from a p-variate normal distribution whose mean vector shifts from $\boldsymbol{\mu}_{0}$ to $\boldsymbol{\mu}_{1}$ on the $\mathrm{r}^{\text {th }}$ observation, that is, 


$$
\begin{aligned}
\mathbf{x}_{i} & \sim N_{p}\left(\boldsymbol{\mu}_{0}, \boldsymbol{\Sigma}\right), \quad i=1,2, \ldots, r-1 \\
& \sim N_{p}\left(\boldsymbol{\mu}_{1}, \boldsymbol{\Sigma}\right), \quad i=r, r+1, r+2 \ldots
\end{aligned}
$$

Lowry, et al. (1992) defined vectors of exponentially weighted moving averages,

$$
\mathbf{z}_{i}=\lambda \mathbf{x}_{i}+(1-\lambda) \mathbf{z}_{i-1}
$$

$\mathrm{i}=1,2, \ldots$, where $\mathbf{z}_{0}=\mathbf{0}$ and $0<\lambda \leq 1$. The MEWMA chart would give an out-of-control signal if

$$
T_{i}^{2}=\mathbf{z}_{i}^{\prime} \mathbf{\Sigma}_{\mathbf{z}_{i}}^{-1} \mathbf{z}_{i}>h
$$

where $\mathrm{h}>0$ is chosen to achieve a specified incontrol ARL and

$$
\boldsymbol{\Sigma}_{\mathbf{z}_{i}}=\frac{\lambda}{2-\lambda}\left[1-(1-\lambda)^{2 i}\right] \boldsymbol{\Sigma} .
$$

The one-variable deletion within the MEWMA statistic removes variables from the $\mathrm{T}_{\mathrm{i}}^{2}$ statistic when a signal is detected. This study examines the removal of one variable and two variables at a time: one-variable deletion removes one variable at a time and recalculates the current $\mathrm{T}_{\mathrm{i}}^{2}$ statistic excluding the removed variable, two-variable deletion removes pairs of variables and recalculates the current $\mathrm{T}_{\mathrm{i}}^{2}$ statistic excluding the removed pair. Given either method, a small, reduced $\mathrm{T}_{\mathrm{i}}^{2}$ statistic would indicate a possible signal source.

\section{One-Variable Deletion}

Assume on the $\mathrm{s}^{\text {th }}$ sample, the MEWMA chart signaled a change $\left(\mathrm{T}_{\mathrm{s}}^{2}>\mathrm{h}\right)$. The $\mathrm{p}$ variables are removed, one at a time, from the calculation of $\mathrm{T}_{\mathrm{s}}^{2}$. Assume the $\mathrm{j}^{\text {th }}$ variable is removed such that

$$
\begin{aligned}
\mathbf{x}_{\mathrm{i}}{ }^{\prime} & =\left(\mathrm{x}_{\mathrm{i} 1}, \mathrm{x}_{\mathrm{i} 2}, \ldots, \mathrm{x}_{\mathrm{i}, \mathrm{j}-1}, \mathrm{x}_{\mathrm{i}, \mathrm{j}+1}, \ldots, \mathrm{x}_{\mathrm{ip}}, \mathrm{x}_{\mathrm{ij}}\right), \\
& =\left(\mathbf{x}_{\mathrm{i}(\mathrm{j})}{ }^{\prime}, \mathrm{x}_{\mathrm{ij}}\right)
\end{aligned}
$$

where $\mathbf{x}_{i(j)}{ }^{\prime}$ is a $(\mathrm{p}-1) \mathrm{x} 1$ vector excluding the $\mathrm{j}^{\text {th }}$ variable. In addition, let $\boldsymbol{\Sigma}_{(j)}$ be the (p-1)x(p-1) principal sub-matrix of $\boldsymbol{\Sigma}$ excluding the $\mathrm{j}^{\text {th }}$ variable. With the $\mathrm{j}^{\text {th }}$ variable removed, the MEWMA equations become

$$
\mathbf{z}_{i(j)}=\lambda \mathbf{x}_{i(j)}+(1-\lambda) \mathbf{z}_{i-1,(j)}
$$

$\mathrm{i}=1,2, \ldots$, s where $\mathbf{z}_{0(j)}=\mathbf{0}$,

$$
T_{i(j)}^{2}=\mathbf{z}_{i(j)}{ }^{\prime} \boldsymbol{\Sigma}_{\mathbf{z}_{i(j)}^{-1}}^{-\mathbf{z}_{i(j)}}
$$

and

$$
\boldsymbol{\Sigma}_{\mathbf{z}_{i(j)}}=\frac{\lambda}{2-\lambda}\left[1-(1-\lambda)^{2 i}\right] \boldsymbol{\Sigma}_{(j)} .
$$

The calculation of $\mathrm{T}_{\mathrm{i}(\mathrm{j})}{ }^{2}$ continues until the $\mathrm{s}^{\text {th }}$ sample.

A graphical comparison of the set of reduced MEWMA statistics $\left\{\mathrm{T}_{\mathrm{s}(1)}{ }^{2}, \mathrm{~T}_{\mathrm{s}(2)}{ }^{2}, \ldots\right.$, $\left.\mathrm{T}_{\mathrm{s}(\mathrm{p})}{ }^{2}\right\}$ to $\mathrm{T}_{\mathrm{s}}{ }^{2}$ should aid in identifying the cause of the signal. The smallest reduced MEWMA statistic may indicate which variable contributed to the signal. For example, if the $1^{\text {st }}$ variable shifts, the reduced MEWMA statistics may resemble Figure 1. A similar analysis is required if more than two variables change. For example, the reduced MEWMA statistics may resemble Figure 2, if the $1^{\text {st }}$ and the $2^{\text {nd }}$ variables shift or may resemble Figure 3 , if the $1^{\text {st }}, 2^{\text {nd }}$ and $3^{\text {rd }}$ variables shift.

Consider a modified example from Lowry, et al. (1992). Assume

$$
\begin{aligned}
\mathbf{x}_{i} & \sim N_{3}\left(\boldsymbol{\mu}_{0}, \boldsymbol{\Sigma}\right), \quad i=1,2, \ldots, 15 \\
& \sim N_{3}\left(\boldsymbol{\mu}_{1}, \boldsymbol{\Sigma}\right), \quad i=16,17,18, \ldots
\end{aligned}
$$

such that:

$$
\boldsymbol{\mu}_{\mathbf{o}}=\left[\begin{array}{l}
0 \\
0 \\
0
\end{array}\right] \text {, }
$$


Figure 1: A General Representation of the Reduced MEWMA Statistics if Variable 1 Shifted

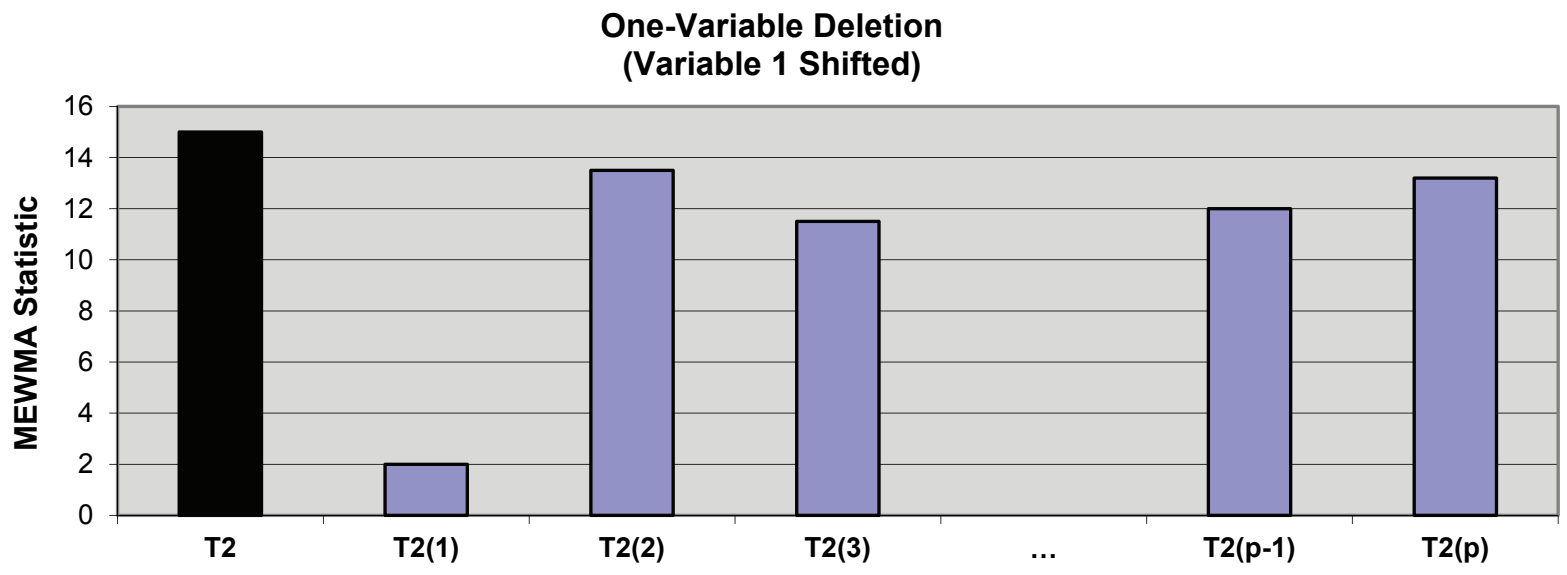

Figure 2: A General Representation of the Reduced MEWMA Statistics if Variables 1 and 2 Shifted

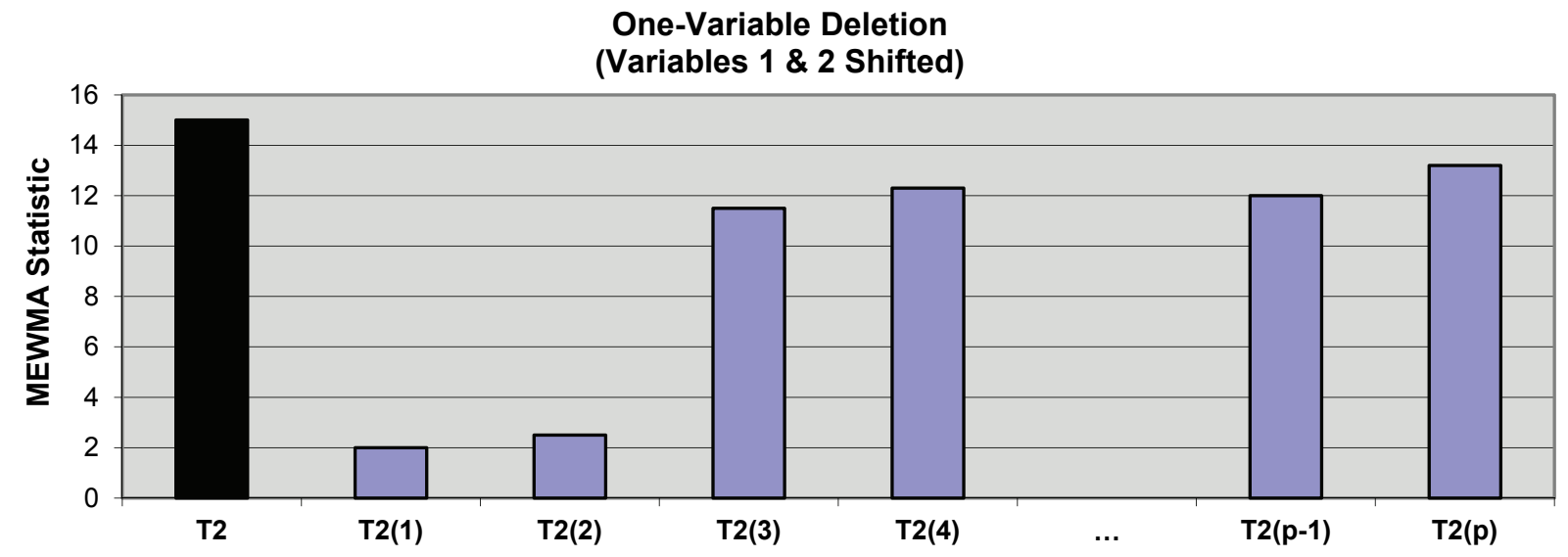

Figure 3: A General Representation of the Reduced MEWMA Statistics if Variables 1, 2 and 3 Shifted

One-Variable Deletion

(Variables 1, 2, \& 3 Shifted)

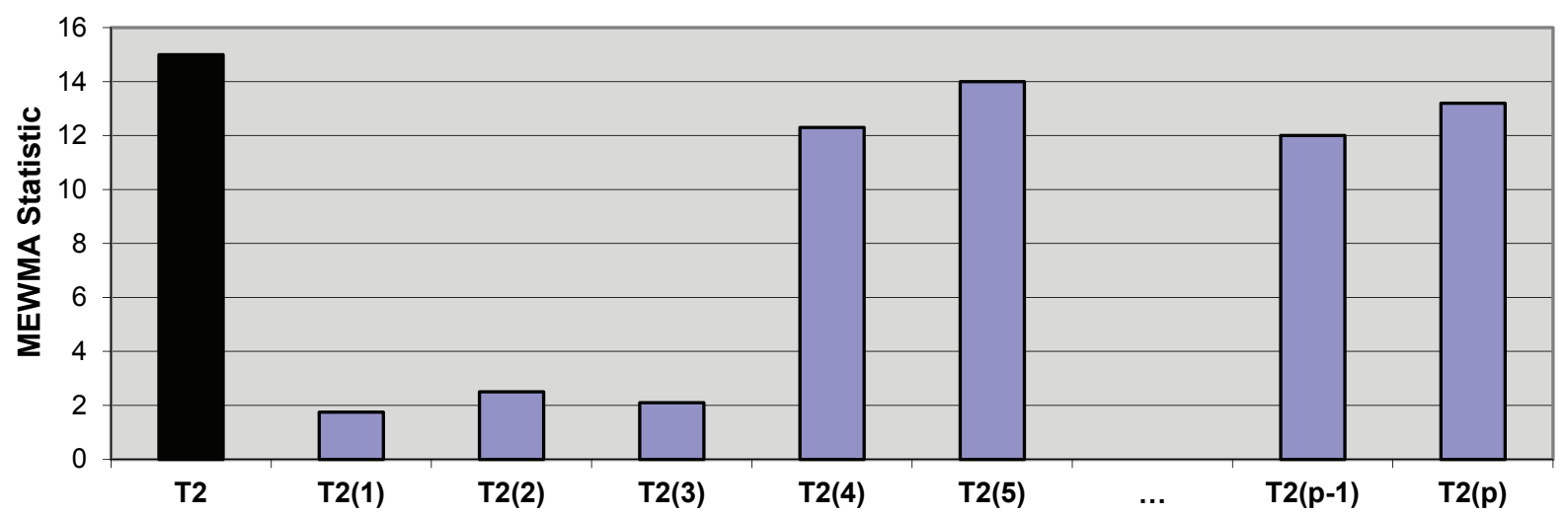


GRAPHICAL EXAMINATION OF VARIABLE DELETION WITHIN THE MEWMA

$$
\boldsymbol{\mu}_{\mathbf{1}}=\left[\begin{array}{c}
\sqrt{2} \\
0 \\
0
\end{array}\right] \text {, }
$$

and

$$
\boldsymbol{\Sigma}=\left[\begin{array}{ccc}
1 & 0.5 & 0.5 \\
0.5 & 1 & 0.5 \\
0.5 & 0.5 & 1
\end{array}\right]
$$

Note that a shift of

$$
\delta=\sqrt{\left(\mu_{1}-\mu_{0}\right)^{\prime} \Sigma^{-1}\left(\mu_{1}-\mu_{0}\right)}=3
$$

occurred on the $16^{\text {th }}$ sample. Table 1 displays a data simulation of these conditions along with the corresponding MEWMA statistics, $\mathrm{T}_{\mathrm{i}}^{2}$. Using $\lambda=0.10$, and $\mathrm{h}=10.97$ (in-control ARL $=200)$, the MEWMA chart signaled on the $21^{\text {st }}$ observation such that $\mathrm{T}_{21}{ }^{2}=11.3551$. However, it is not apparent which variable changed through an examination of the data or the MEWMA chart.

Using the data from Table 1, the first variable is removed from the calculation of the MEWMA statistic. Variables 2 and 3 are used to recalculate a reduced MEWMA statistic, $\mathrm{T}_{\mathrm{i}(1)}^{2}$. The reduced covariance matrix is then:

$$
\Sigma_{(1)}=\left[\begin{array}{cc}
1 & 0.5 \\
0.5 & 1
\end{array}\right]
$$

The reduced MEWMA statistic, $\mathrm{T}_{\mathrm{i}(1)}^{2}$, is calculated for $\mathrm{i}=1,2, \ldots, 21$ and displayed in Table 2. Note that, on the $21^{\text {st }}$ sample, $\mathrm{T}_{21(1)}^{2}=$ 0.9358 represents the reduced MEWMA statistic with the contribution of the first variable removed.

Repeating the one-variable deletion procedure for the remaining two variables, the reduced MEWMA statistic excluding variable 2 is $\mathrm{T}_{21(2)}^{2}=11.3282$ and the reduced MEWMA statistic excluding variable 3 is $\mathrm{T}_{21(3)}^{2}=9.0015$. Comparing the three reduced MEWMA statistics to the MEWMA statistic $\mathrm{T}_{21}^{2}=11.3551, \quad$ it is likely variable 1 contributed to the signal. Figure 4 displays the MEWMA statistic along with the three reduced MEWMA statistics.

Two-Variable Deletion

Assume on the $\mathrm{s}^{\text {th }}$ sample, the MEWMA chart signaled a change $\left(\mathrm{T}_{\mathrm{s}}{ }^{2}>\mathrm{h}\right)$. The $\mathrm{p}$ variables are removed, two at a time, from the calculation of $\mathrm{T}_{\mathrm{s}}^{2}$. Assume the $\mathrm{j}^{\text {th }}$ and $\mathrm{k}^{\text {th }}$ variables are to be removed. Now let

$$
\begin{aligned}
\mathbf{x}_{\mathrm{i}}{ }^{\prime} & =\left(\begin{array}{l}
\mathrm{x}_{\mathrm{i} 1}, \mathrm{x}_{\mathrm{i} 2}, \ldots, \mathrm{x}_{\mathrm{i}, \mathrm{j}-1}, \mathrm{x}_{\mathrm{i}, \mathrm{j}+1}, \ldots, \\
\mathrm{x}_{\mathrm{i}, \mathrm{k}-1}, \mathrm{x}_{\mathrm{i}, \mathrm{k}+1}, \ldots \mathrm{x}_{\mathrm{ip}}, \mathrm{x}_{\mathrm{ij}}, \mathrm{x}_{\mathrm{ik}}
\end{array}\right), \\
& =\left(\mathbf{x}_{\mathrm{i}(\mathrm{j}, \mathrm{k})}, \mathrm{x}_{\mathrm{ij}}, \mathrm{x}_{\mathrm{ik}}\right)
\end{aligned}
$$

where $\left.\mathbf{x}_{i(j, k)}\right)^{\prime}$ is a $(\mathrm{p}-2) \mathrm{x} 1$ vector excluding the $\mathrm{j}^{\text {th }}$ and $\mathrm{k}^{\text {th }}$ variables. In addition, let $\boldsymbol{\Sigma}_{(j, k)}$ be the $(\mathrm{p}-2) \mathrm{x}(\mathrm{p}-2)$ principal sub-matrix of $\boldsymbol{\Sigma}$ excluding the $\mathrm{j}^{\text {th }}$ and $\mathrm{k}^{\text {th }}$ variables. With the $\mathrm{j}^{\text {th }}$ and $\mathrm{k}^{\text {th }}$ variables removed, the MEWMA equations become

$$
\mathbf{z}_{i(j, k)}=\lambda \mathbf{x}_{i(j, k)}+(1-\lambda) \mathbf{z}_{i-1,(j, k)}
$$

$\mathrm{i}=1,2, \ldots$, s where $\mathbf{z}_{0(j, k)}=\mathbf{0}$,

$$
\left.T_{i(j, k)}^{2}=\mathbf{z}_{i(j, k)}\right)^{\prime \Sigma_{\mathbf{z}_{i(j, k)}}^{-1}} \mathbf{z}_{i(j, k)}
$$

and

$$
\boldsymbol{\Sigma}_{\mathbf{z}_{i(j, k)}}=\frac{\lambda}{2-\lambda}\left[1-(1-\lambda)^{2 i}\right] \boldsymbol{\Sigma}_{(j, k)} .
$$

The calculation of $\mathrm{T}_{\mathrm{i}(\mathrm{j}, \mathrm{k})}{ }^{2}$ is continued until the $\mathrm{s}^{\text {th }}$ sample. 
JAY R. SCHAFFER \& SHAWN VANDENHUL

Table 1: Simulated Process with Corresponding MEWMA Statistics, $\mathrm{T}_{\mathrm{i}}^{2}$

\begin{tabular}{|c|c|c|c|c|}
\hline $\mathrm{i}$ & $\mathrm{x}_{1}$ & $\mathrm{x}_{2}$ & $\mathrm{x}_{3}$ & $\mathrm{~T}_{\mathrm{i}}^{2}$ \\
\hline 1 & 0.1307 & 0.5629 & -0.7255 & 0.7203 \\
\hline 2 & 1.5662 & -0.3972 & 0.5767 & 2.3382 \\
\hline 3 & 0.5733 & 1.4400 & 1.4343 & 1.9161 \\
\hline 4 & -0.0342 & -0.0966 & 0.8100 & 1.6907 \\
\hline 5 & 0.2922 & 0.0853 & -0.3257 & 1.2270 \\
\hline 6 & -0.2988 & -0.7700 & 0.3948 & 1.1400 \\
\hline 7 & 0.1389 & 0.4851 & 0.1806 & 0.8966 \\
\hline 8 & -0.0184 & -0.5328 & 0.4871 & 1.3231 \\
\hline 9 & 0.6751 & -0.3919 & -1.4367 & 1.1445 \\
\hline 10 & -2.5591 & -1.4792 & -2.3697 & 1.0214 \\
\hline 11 & -1.8930 & 0.4438 & -0.9319 & 2.2448 \\
\hline 12 & -0.4950 & 0.4710 & -0.0471 & 2.6071 \\
\hline 13 & -1.1572 & 0.8478 & -0.5695 & 5.2338 \\
\hline 14 & 0.2098 & -0.8472 & 0.1777 & 2.7816 \\
\hline 15 & 0.0101 & 0.1780 & 0.9616 & 2.0170 \\
\hline 16 & 1.1233 & -0.6925 & -1.2685 & 1.1097 \\
\hline 17 & 0.8364 & -1.5027 & -0.1821 & 1.6985 \\
\hline 18 & 0.6587 & 1.0085 & 0.5520 & 0.8009 \\
\hline 19 & 2.3631 & 2.1432 & 0.9458 & 2.0496 \\
\hline 20 & 2.4894 & 0.2182 & -0.2358 & 6.7361 \\
\hline 21 & 2.3260 & 0.7702 & 0.5218 & 11.3551 \\
\hline
\end{tabular}

Table 2: Reduced MEWMA Statistics, $\mathrm{T}_{\mathrm{i}(1)}^{2}$

\begin{tabular}{|c|c|c|c|c|c|c|c|}
\hline $\mathrm{i}$ & 1 & 2 & 3 & 4 & 5 & 6 & 7 \\
\hline $\mathbf{T}_{\mathbf{i}(\mathbf{1})}^{\mathbf{2}}$ & 1.6690 & 0.0192 & 1.1522 & 1.4192 & 0.7580 & 0.9119 & 0.7640 \\
\hline $\mathbf{i}$ & $\mathbf{8}$ & $\mathbf{9}$ & $\mathbf{1 0}$ & $\mathbf{1 1}$ & $\mathbf{1 2}$ & $\mathbf{1 3}$ & $\mathbf{1 4}$ \\
\hline $\mathbf{T}_{\mathbf{i}(\mathbf{1})}^{\mathbf{2}}$ & 1.2226 & 0.0973 & 0.9894 & 1.5824 & 1.4426 & 2.5004 & 1.2420 \\
\hline $\mathbf{i}$ & $\mathbf{1 5}$ & $\mathbf{1 6}$ & $\mathbf{1 7}$ & $\mathbf{1 8}$ & $\mathbf{1 9}$ & $\mathbf{2 0}$ & $\mathbf{2 1}$ \\
\hline $\mathbf{T}_{\mathbf{i}(\mathbf{1})}^{\mathbf{2}}$ & 0.2939 & 1.0651 & 1.3763 & 0.4595 & 0.5040 & 0.6895 & 0.9358 \\
\hline
\end{tabular}


Figure 4: MEWMA $T^{2}$ Statistic and the Three Reduced MEWMA Statistics

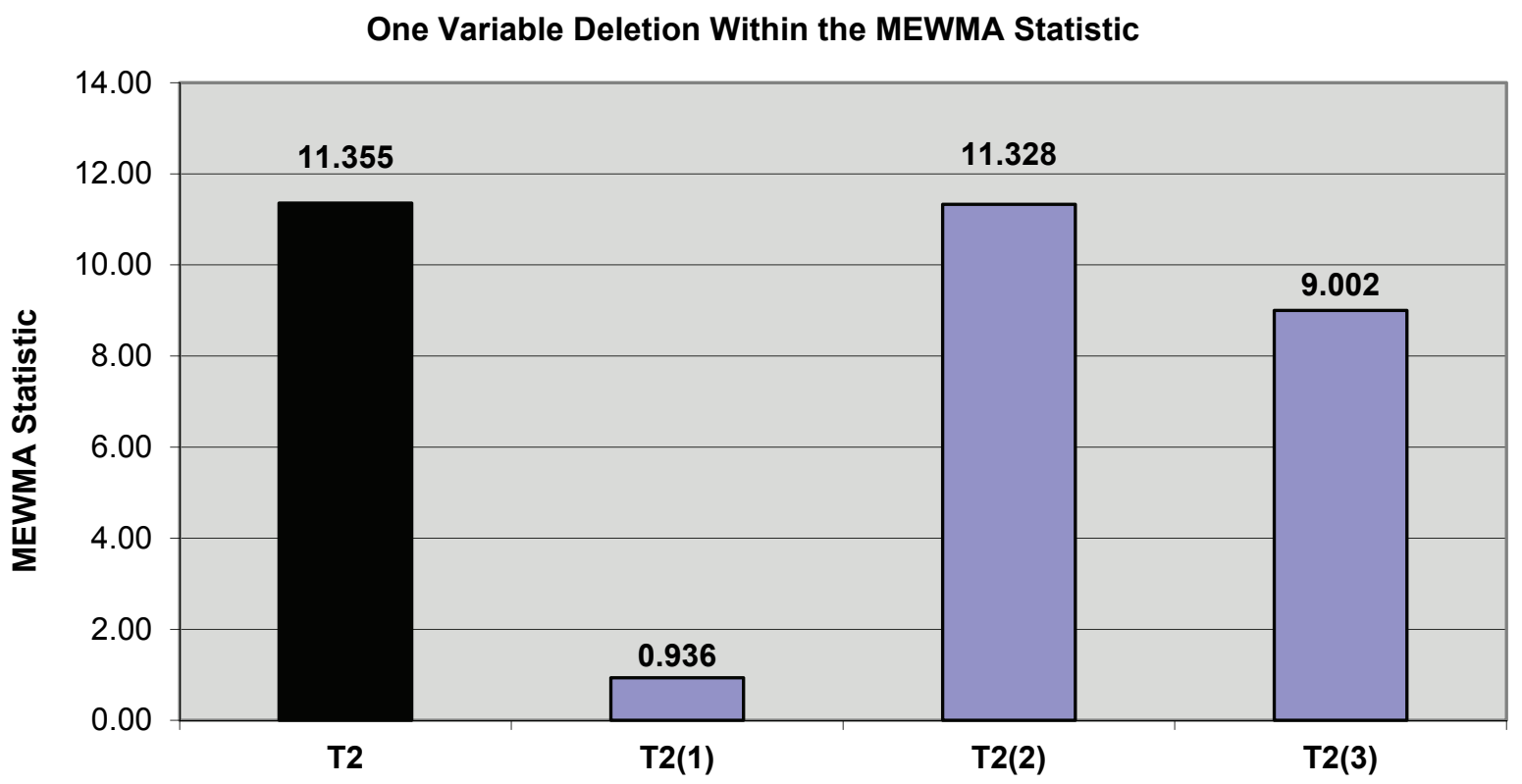

A graphical comparison of the set of reduced MEWMA statistics $\left\{\mathrm{T}_{\mathrm{s}(1,2)}{ }^{2}, \mathrm{~T}_{\mathrm{s}(1,3)}{ }^{2}, \ldots\right.$, $\left.\mathrm{T}_{\mathrm{s}(1, \mathrm{p})}{ }^{2}, \mathrm{~T}_{\mathrm{s}(2,3)}{ }^{2}, \mathrm{~T}_{\mathrm{s}(2,4)}^{2}, \ldots, \mathrm{T}_{\mathrm{s}(\mathrm{p}-1, \mathrm{p})}^{2}\right\}$ to $\mathrm{T}_{\mathrm{s}}^{2}$ should aids in identifying the cause of the signal. The smallest group of reduced MEWMA statistics may indicate which variable contributed to the signal. For example, if the $1^{\text {st }}$ variable shifts, the reduced MEWMA statistics may resemble Figure 5, such that the group of reduced MEWMA statistics associated with the first variable is uniformly smaller than the others.

A more detailed analysis is required if two variables have shifted. The smallest reduced MEWMA statistic may indicate which pair of variables changed. In addition, any reduced MEWMA statistic associated with one of the pair of variables that shifted may be slightly larger, yet smaller than any other reduced MEWMA statistic not associated with the pair that changed. The reduced MEWMA statistics may resemble Figure 6 , if the $1^{\text {st }}$ and the $2^{\text {nd }}$ variables shift. A similar analysis is required if three variables have shifted. The reduced MEWMA statistics may resemble Figure 7, if the $1^{\text {st }}, 2^{\text {nd }}$ and $3^{\text {rd }}$ variables shift.
Consider a modified example from Lowry, et al. (1992). Assume

$$
\begin{aligned}
\mathbf{x}_{i} & \sim N_{4}\left(\boldsymbol{\mu}_{0}, \boldsymbol{\Sigma}\right), \quad i=1,2, \ldots, 15 \\
& \sim N_{4}\left(\boldsymbol{\mu}_{1}, \boldsymbol{\Sigma}\right), \quad i=16,17,18, \ldots
\end{aligned}
$$

such that:

$$
\begin{gathered}
\boldsymbol{\mu}_{\mathbf{0}}=\left[\begin{array}{l}
0 \\
0 \\
0 \\
0
\end{array}\right], \\
\boldsymbol{\mu}_{\mathbf{1}}=\left[\begin{array}{c}
\sqrt{3 / 2} \\
\sqrt{3 / 2} \\
0 \\
0
\end{array}\right],
\end{gathered}
$$

and

$$
\boldsymbol{\Sigma}=\left[\begin{array}{cccc}
1 & 0.5 & 0.5 & 0.5 \\
0.5 & 1 & 0.5 & 0.5 \\
0.5 & 0.5 & 1 & 0.5 \\
0.5 & 0.5 & 0.5 & 1
\end{array}\right]
$$


Figure 5: A General Representation of the Reduced MEWMA Statistics if Variable 1 Shifted

Two-Variable Deletion (Variable 1 Shifted)

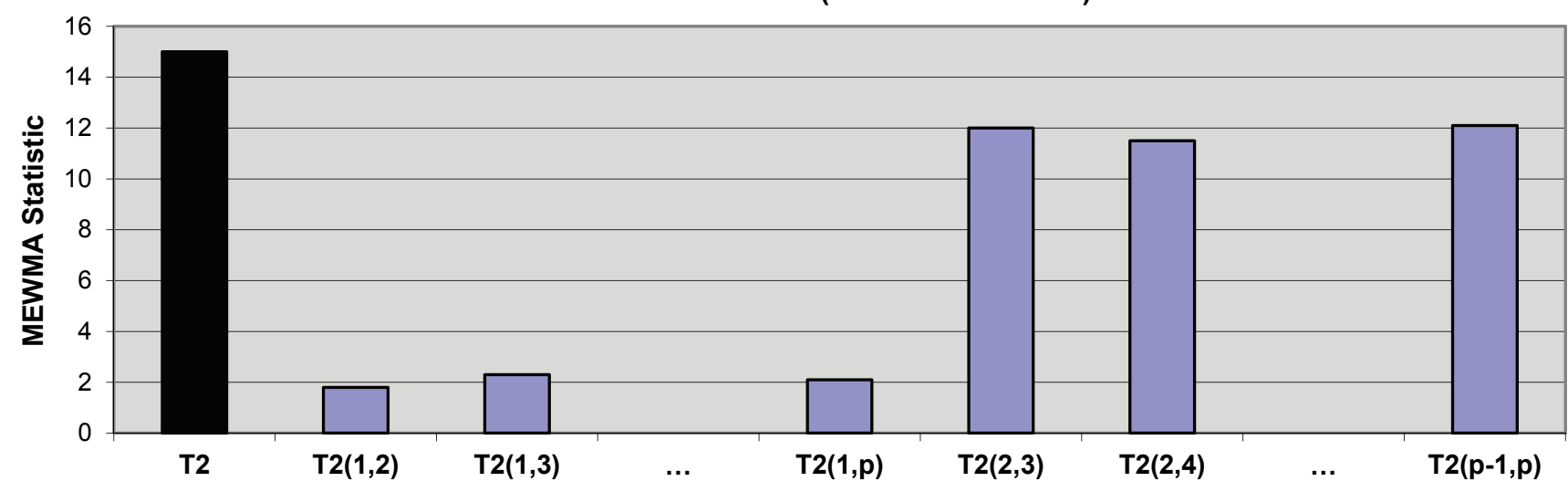

Figure 6: A General Representation of the Reduced MEWMA Statistics if Variables 1 and 2 Shifted

Two-Variable Deletion (Variables 1 \& 2 Shifted)

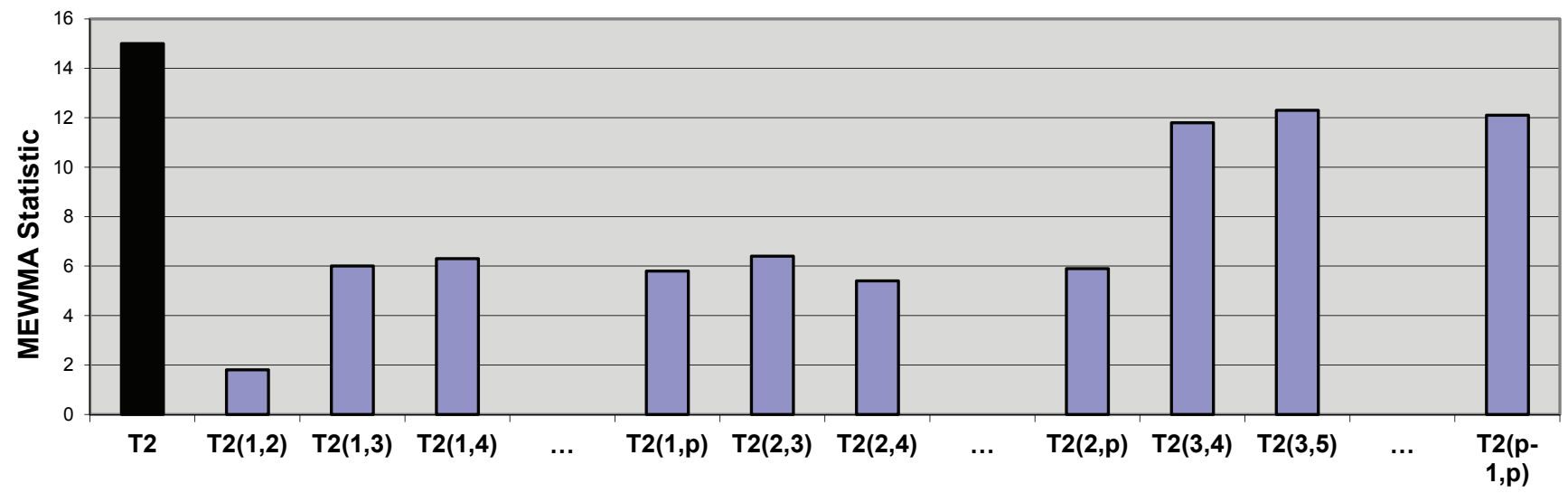

Figure 7: A General Representation of the Reduced MEWMA Statistics if Variables 1, 2 and 3 Shifted

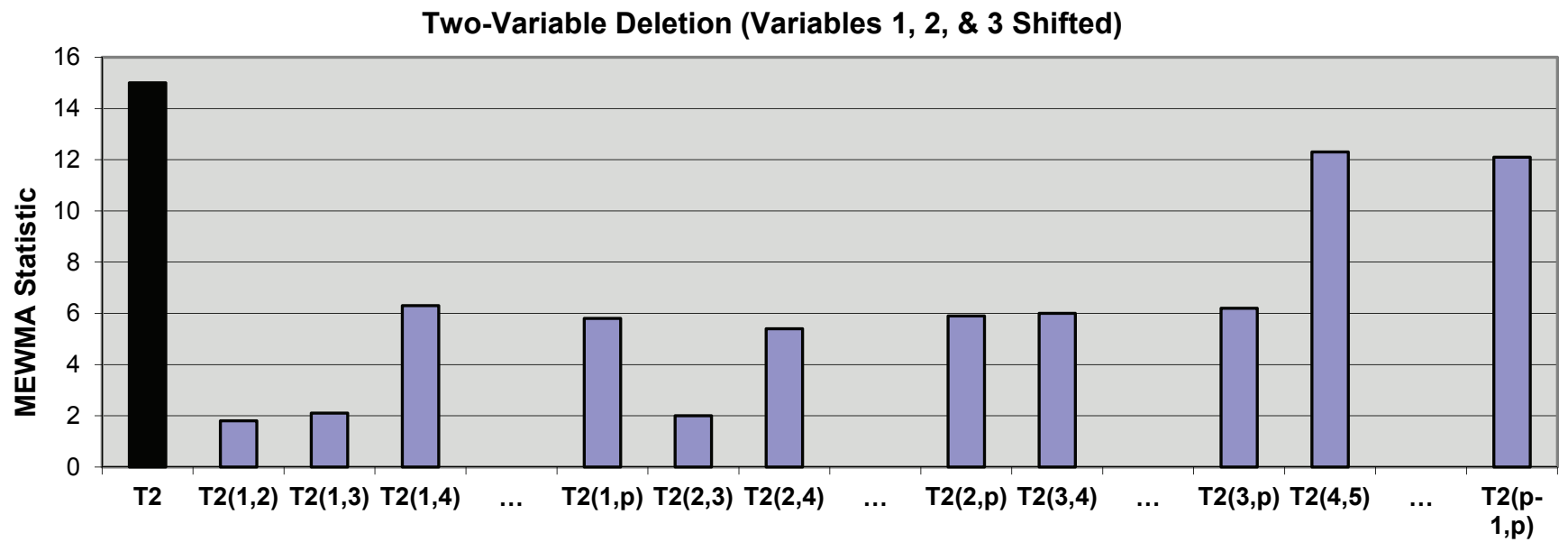


Table 3: Simulated Process with Corresponding MEWMA Statistics, $\mathrm{T}_{\mathrm{i}}^{2}$

\begin{tabular}{|c|c|c|c|c|c|}
\hline $\mathrm{i}$ & $\mathrm{X}_{1}$ & $\mathrm{X}_{2}$ & $\mathrm{X}_{3}$ & $\mathrm{X}_{4}$ & $\mathrm{~T}_{\mathrm{i}}^{2}$ \\
\hline 1 & 0.502 & 0.130 & 0.150 & 0.086 & 0.296 \\
\hline 2 & -0.862 & -0.877 & -0.515 & 0.025 & 0.531 \\
\hline 3 & 0.630 & 1.914 & 1.396 & 2.179 & 2.605 \\
\hline 4 & 0.448 & -0.422 & -0.036 & 0.692 & 2.816 \\
\hline 5 & -0.995 & -0.605 & -0.772 & -1.700 & 0.402 \\
\hline 6 & -0.090 & 1.305 & -1.037 & -0.812 & 1.540 \\
\hline 7 & -0.951 & -1.808 & -0.142 & 0.197 & 0.772 \\
\hline 8 & -0.549 & -0.136 & -0.350 & 0.671 & 1.857 \\
\hline 9 & 0.068 & -0.312 & -2.316 & 0.680 & 5.749 \\
\hline 10 & 2.132 & 0.072 & -1.062 & -1.362 & 6.477 \\
\hline 11 & -0.738 & 0.141 & 0.030 & 1.026 & 5.355 \\
\hline 12 & 1.293 & -1.380 & -0.687 & 0.953 & 9.455 \\
\hline 13 & -0.249 & -0.954 & -1.079 & -0.001 & 11.282 \\
\hline 14 & 0.733 & -1.432 & 0.480 & -0.406 & 10.842 \\
\hline 15 & 0.704 & -0.170 & -0.120 & 0.159 & 10.970 \\
\hline 16 & 2.036 & 2.011 & 1.985 & 1.179 & 7.910 \\
\hline 17 & 0.950 & 3.354 & 1.741 & 1.824 & 5.742 \\
\hline 18 & 2.044 & 0.054 & 0.281 & -0.287 & 8.560 \\
\hline 19 & 0.858 & 0.593 & 0.151 & -0.932 & 9.069 \\
\hline 20 & 1.231 & 2.576 & -0.213 & -0.428 & 13.793 \\
\hline
\end{tabular}

Note that a shift of

$$
\delta=\sqrt{\left(\mu_{1}-\mu_{0}\right)^{\prime} \Sigma^{-1}\left(\mu_{1}-\mu_{0}\right)}=3
$$

occurred on the $16^{\text {th }}$ sample. Table 3 displays a data simulation of these conditions along with the corresponding MEWMA $\mathrm{T}_{\mathrm{i}}^{2}$ statistics. Using $\lambda=0.10$ and $\mathrm{h}=12.93$ (in-control $\mathrm{ARL}=$ 200), the MEWMA chart signaled on the $20^{\text {th }}$ observation such that $T_{20}^{2}=13.793$.
Using equations (9)-(11), the reduced MEWMA statistics are $T_{20(1,2)}^{2}=0.296$, $T_{20(1,3)}^{2}=4.771, T_{20(1,4)}^{2}=5.213, T_{20(2,3)}^{2}=$ $10.481, T_{20(2,4)}^{2}=11.246$, and $T_{20(3,4)}^{2}=$ 9.674. Figure 8 displays the reduced MEWMA statistics. Note that $T_{20(1,2)}^{2}=0.296$ indicates variables 1 and 2 likely contributed to the signal. 
Figure 8: MEWMA T ${ }^{2}$ Statistic and the Reduced MEWMA Statistics

Two-Variable Deletion Within the MEWMA Statistic

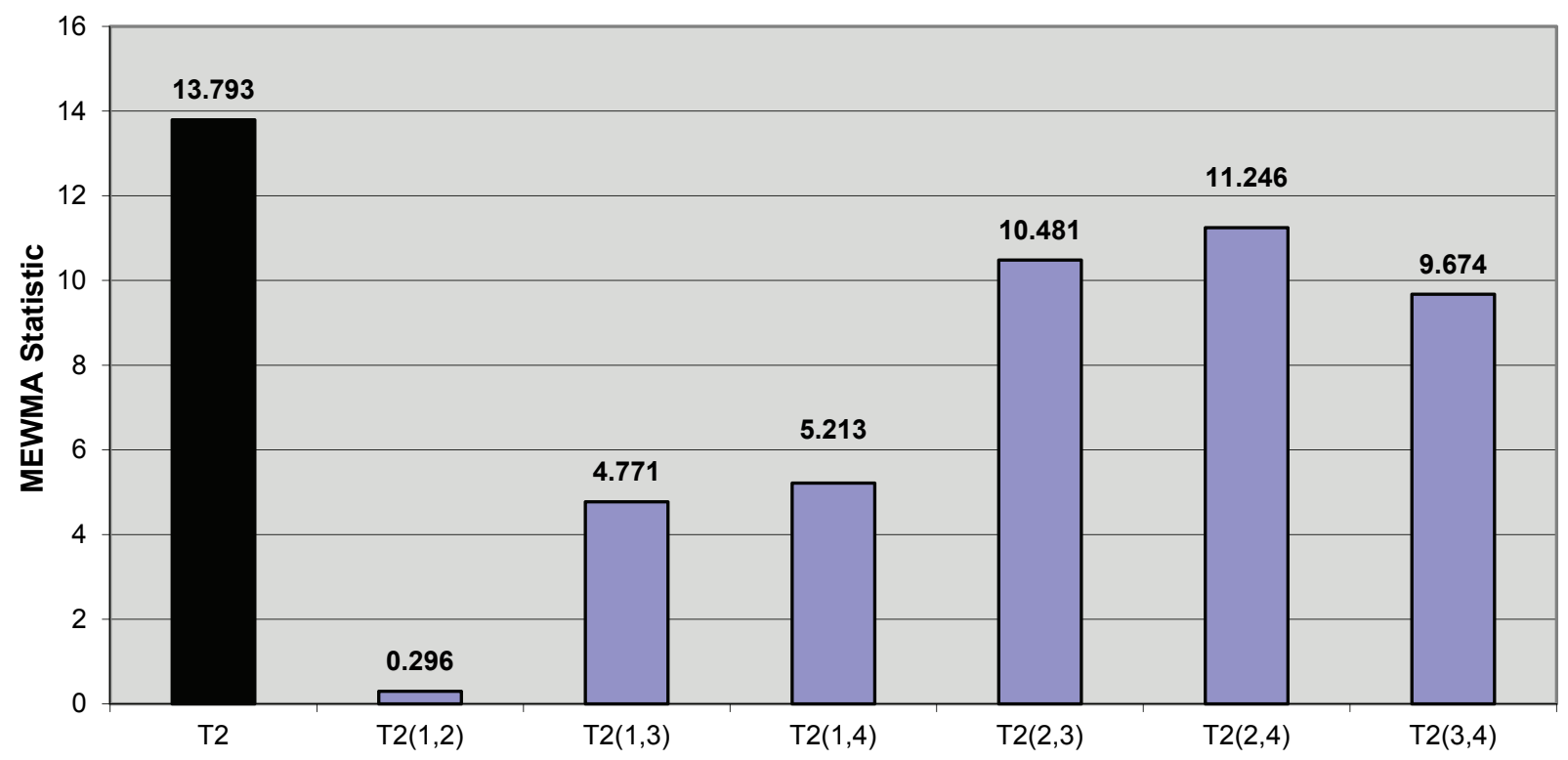

Methodology

Simulations were conducted to estimate the probability of correctly identifying the source of the MEWMA chart's signal. Consider a sequence of independent observations from a $\mathrm{p}$ variate normal distribution whose mean vector shifts from $\boldsymbol{\mu}_{0}=\mathbf{0}$ to $\boldsymbol{\mu}_{1}$ on the $16^{\text {th }}$ observation, that is,

$$
\begin{aligned}
\mathbf{x}_{i} & \sim N_{p}(\mathbf{0}, \boldsymbol{\Sigma}), \quad i=1,2, \ldots, 15 \\
& \sim N_{p}\left(\boldsymbol{\mu}_{1}, \boldsymbol{\Sigma}\right), \quad i=16,17,18 \ldots
\end{aligned}
$$

where

$$
\boldsymbol{\Sigma}=\left[\begin{array}{ccccc}
1 & 0.5 & 0.5 & \ldots & 0.5 \\
0.5 & 1 & 0.5 & \ldots & 0.5 \\
0.5 & 0.5 & \ddots & \ddots & \vdots \\
\vdots & \vdots & \ddots & 1 & 0.5 \\
0.5 & 0.5 & \ldots & 0.5 & 1
\end{array}\right]_{p x p}
$$

Forty conditions were examined using $\mathrm{p}=3,4,5$ and 10; five different $\boldsymbol{\mu}_{1}$ such that $\delta=1$; and five different $\boldsymbol{\mu}_{1}$ such that $\delta=3$. The vectors $\boldsymbol{\mu}_{1}$ are constructed such that (1) one variable shifts, (2) two variables shift equally, (3) two variables shift unequally, (4) three variables shift equally or (5) three variables shift unequally. Tables 4 and 5 display the conditions examined such that $\delta=1$ and $\delta=3$ respectively. When $\mathrm{p}=10$, approximate decimal values were used in place of exact fractions.

\section{Results}

One-Variable Deletion Analysis

If one variable shifts, a one-variable deletion is considered to be a success if the smallest reduced statistic correctly identified the variable that changed. If two variables shift, the one-variable deletion is considered to be a success if the two smallest reduced statistics correctly identify the two variables that changed. If three variables shift, the one-variable deletion is considered to be a success if the three smallest reduced statistics correctly identify the three 
GRAPHICAL EXAMINATION OF VARIABLE DELETION WITHIN THE MEWMA

Table 4: Twenty Conditions Examined when $\delta=1$

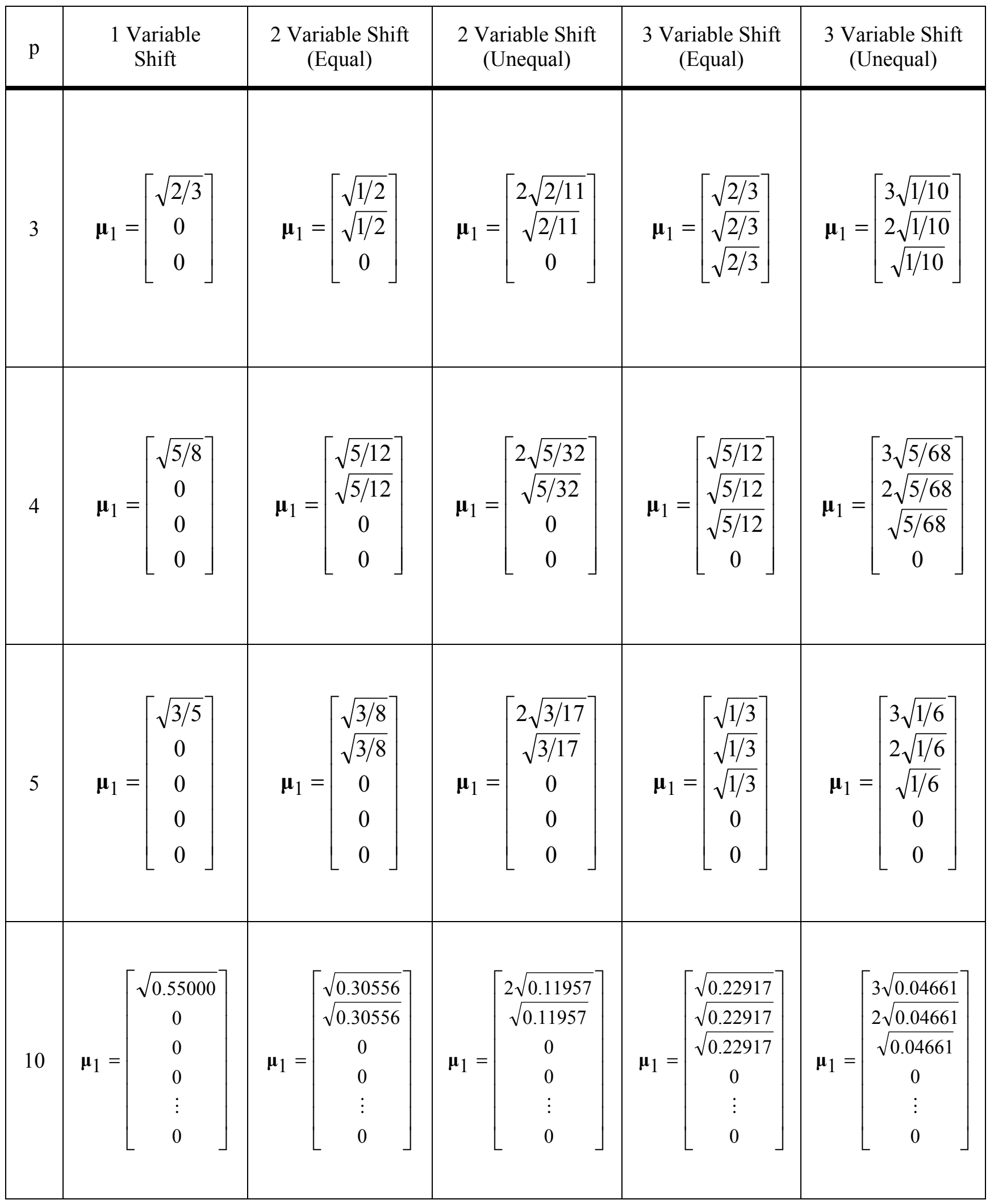


JAY R. SCHAFFER \& SHAWN VANDENHUL

Table 5: Twenty Conditions Examined when $\delta=3$

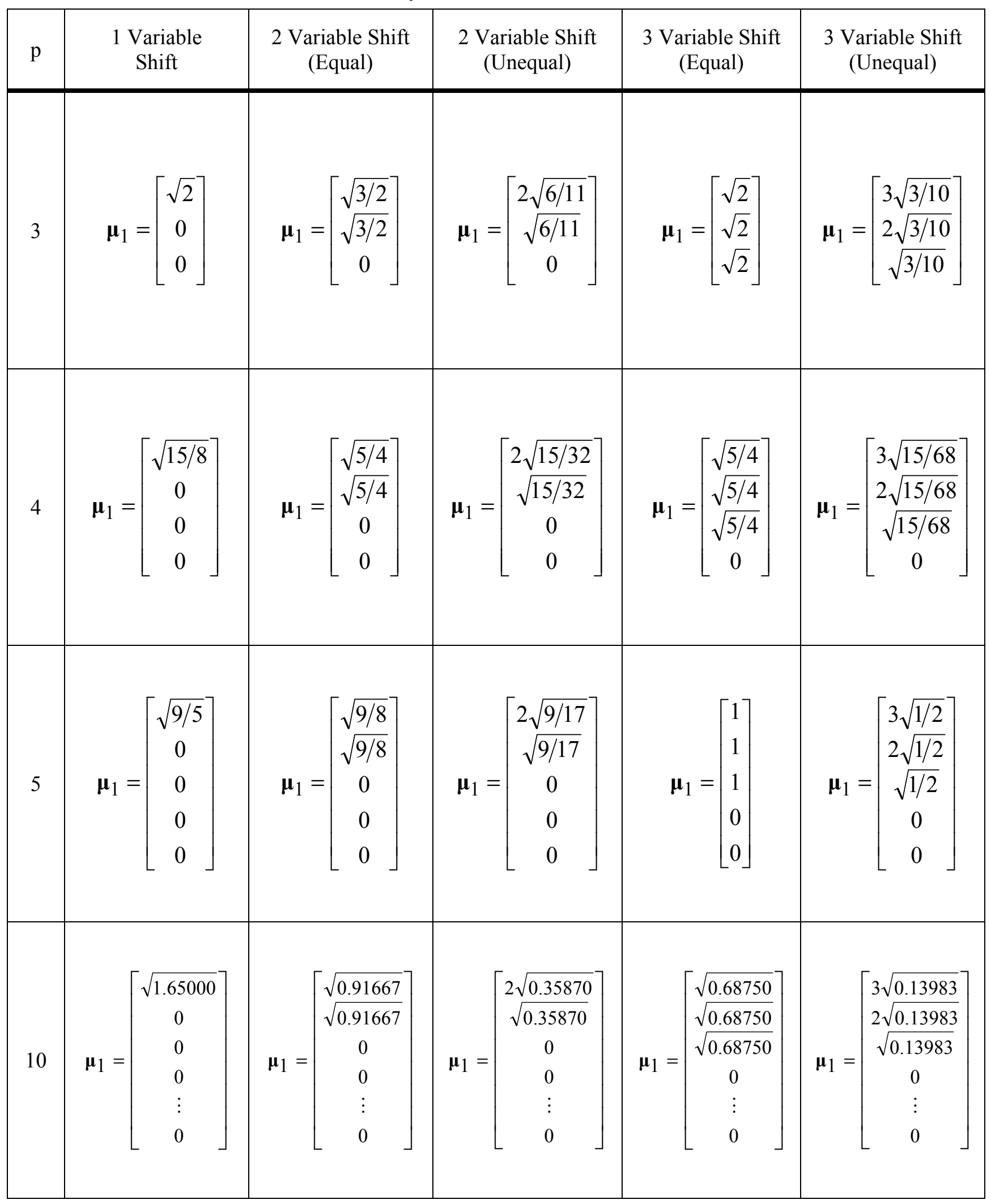




\section{GRAPHICAL EXAMINATION OF VARIABLE DELETION WITHIN THE MEWMA}

variables that changed. These definitions are similar to the examples shown in Figures 1-3.

MEWMA simulations were conducted using $\delta=1$ and a one variable shift such that 10,000 out of control signals were obtained. Using $\mathrm{p}=3, \mathrm{~h}=10.97$, and $\lambda=0.10$, it was found that the smallest reduced MEWMA statistic correctly identified the variable that changed in $85.24 \%$ of the simulations. Using $\mathrm{p}=$ $4, \mathrm{~h}=12.93, \lambda=0.10$, it was found that the smallest reduced MEWMA statistic correctly identified the variable that changed in $84.73 \%$ of the simulations. In addition, using $\mathrm{p}=5, \mathrm{~h}=$ 14.74 , and $\lambda=0.10$, showed that the smallest reduced MEWMA statistic correctly identified the variable that changed in $83.84 \%$ of the simulations. Using $\mathrm{p}=10, \mathrm{~h}=22.91$, and $\lambda=$ 0.10 , it was found that the smallest reduced MEWMA statistic correctly identified the variable that changed in $81.85 \%$ of the simulations. Simulations using $\delta=3$ and a one variable shift produced better results such that when $\mathrm{p}=3,4,5$ and 10 , the smallest reduced MEWMA statistic successfully identified the variable that changed in $88.53 \%, 87.58 \%$, $87.18 \%$ and $86.43 \%$ of the simulations respectively.

The success rate of one-variable deletion correctly identifying the source of the signal declines as the number of variables shifting increases. For example, using $\mathrm{p}=3, \mathrm{~h}=10.97, \lambda$ $=0.10, \delta=1$ and an equal-sized two variable shift, the two smallest reduced MEWMA statistics correctly identify the two variables that shifted in $26.89 \%$ of the 10,000 simulations. The success rate rapidly declines when three variables shift and the three smallest reduced MEWMA statistics are used to identify the variables that changed. Figures 9 and 10 display the success rates of one-variable deletion when $\delta$ $=1$ and $\delta=3$ respectively.

\section{Two-Variable Deletion Analysis}

If one variable shifts, the two-variable deletion is considered to be a success if the $(p-1)$ smallest reduced MEWMA statistics correctly identify the variable that changed. If two variables shift, the two-variable deletion is considered to be a success if the smallest reduced MEWMA statistics correctly identify the two variables that changed. If three variables shift, the two-variable deletion is considered to be a success if the three smallest reduced MEWMA statistics correctly identify the three variables that changed. These definitions are similar to the examples shown in Figures 5-7.

MEWMA simulations were conducted using $\delta=1$ and a one variable shift such that 10,000 out of control signals were obtained. Using $p=3, h=10.97$, and $\lambda=0.10$, it was found that the two smallest reduced MEWMA statistics correctly identified the variable that changed in $87.05 \%$ of the simulations. Using $\mathrm{p}=$ $4, \mathrm{~h}=12.93, \lambda=0.10$, it was found that the three smallest reduced MEWMA statistics correctly identified the variable that changed in $77.58 \%$ of the simulations. In addition, using $\mathrm{p}=5, \mathrm{~h}=$ 14.74, and $\lambda=0.10$, showed that the four smallest reduced MEWMA statistics correctly identified the variable that changed in $76.33 \%$ of the simulations. Using $\mathrm{p}=10, \mathrm{~h}=22.91$, and $\lambda$ $=0.10$, it was found that the nine smallest reduced MEWMA statistics correctly identified the variable that changed in $74.28 \%$ of the simulations. Simulations using $\delta=3$ and a one variable shift produced similar or better results such that when $\mathrm{p}=3,4,5$ and 10 , the $(\mathrm{p}-1)$ smallest reduced MEWMA statistics successfully identified the variable that changed in $85.61 \%, 81.77 \%, 84.61 \%$ and $80.38 \%$ of the simulations respectively.

The success rate of two-variable deletion correctly identifying the source of the signal decreases when two variables shift. However, the decrease is not as pronounced as the one-variable deletion. For example, using $\mathrm{p}$ $=3, \mathrm{~h}=10.97, \lambda=0.10, \delta=1$ and an equalsized two variable shift, the smallest reduced MEWMA statistic correctly identifies the two variables that shifted in $77.02 \%$ of the 10,000 simulations. Figures 11 and 12 display the success rates of two variable deletion when $\delta=1$ and $\delta=3$ respectively. In addition, there tends to be a slight decrease in the success rate when comparing an unequal shift to an equal shift. The success rate rapidly declines when three variables shift and the three smallest reduced MEWMA statistics are used to identify the variables that changed. 
Figure 9: Success Rate of One-Variable Deletion when $\delta=1$

\section{One-Variable Deletion $(\delta=1)$}

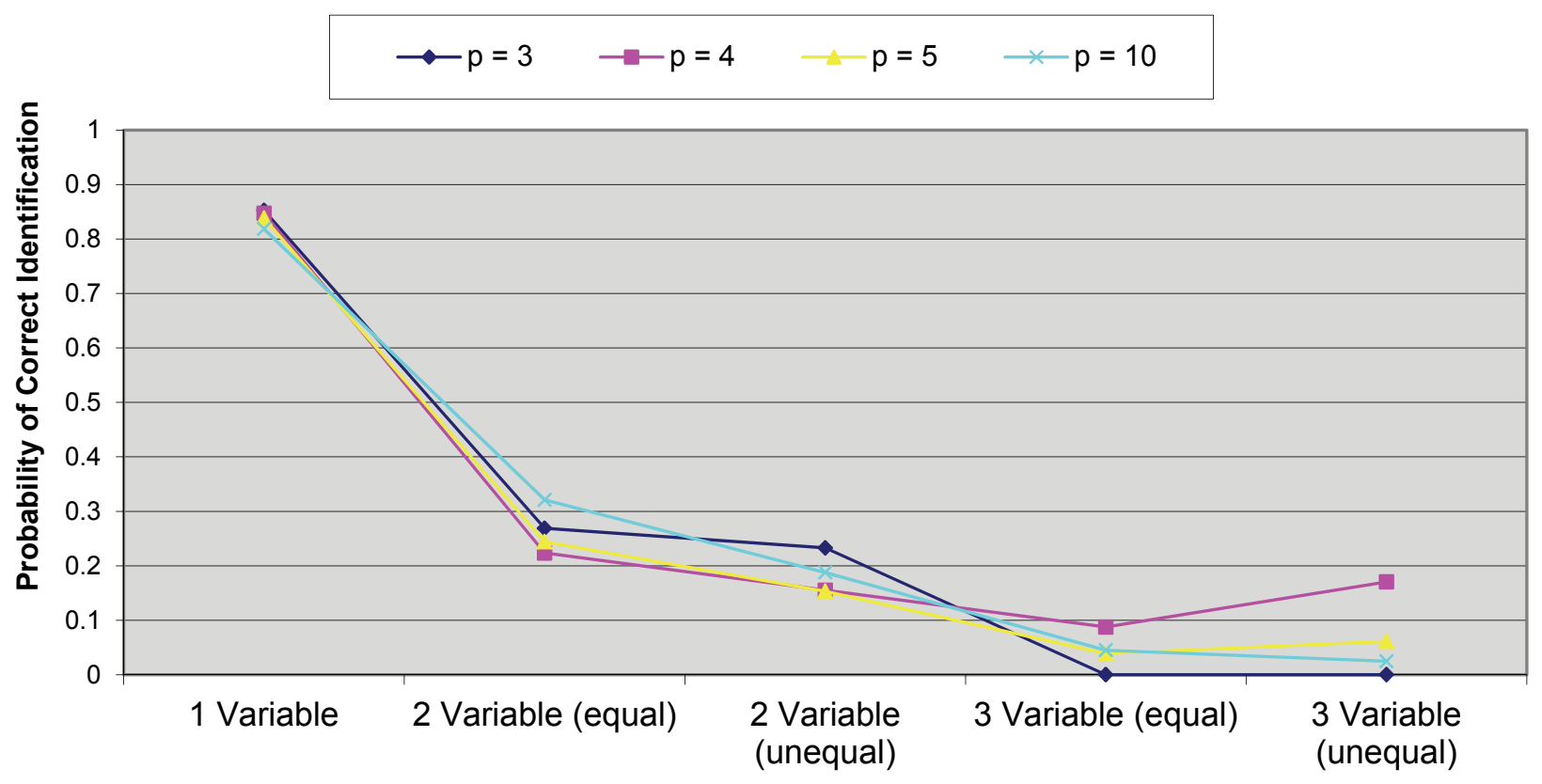

Type of Shift

Figure 10: Success Rate of One-Variable Deletion when $\delta=3$

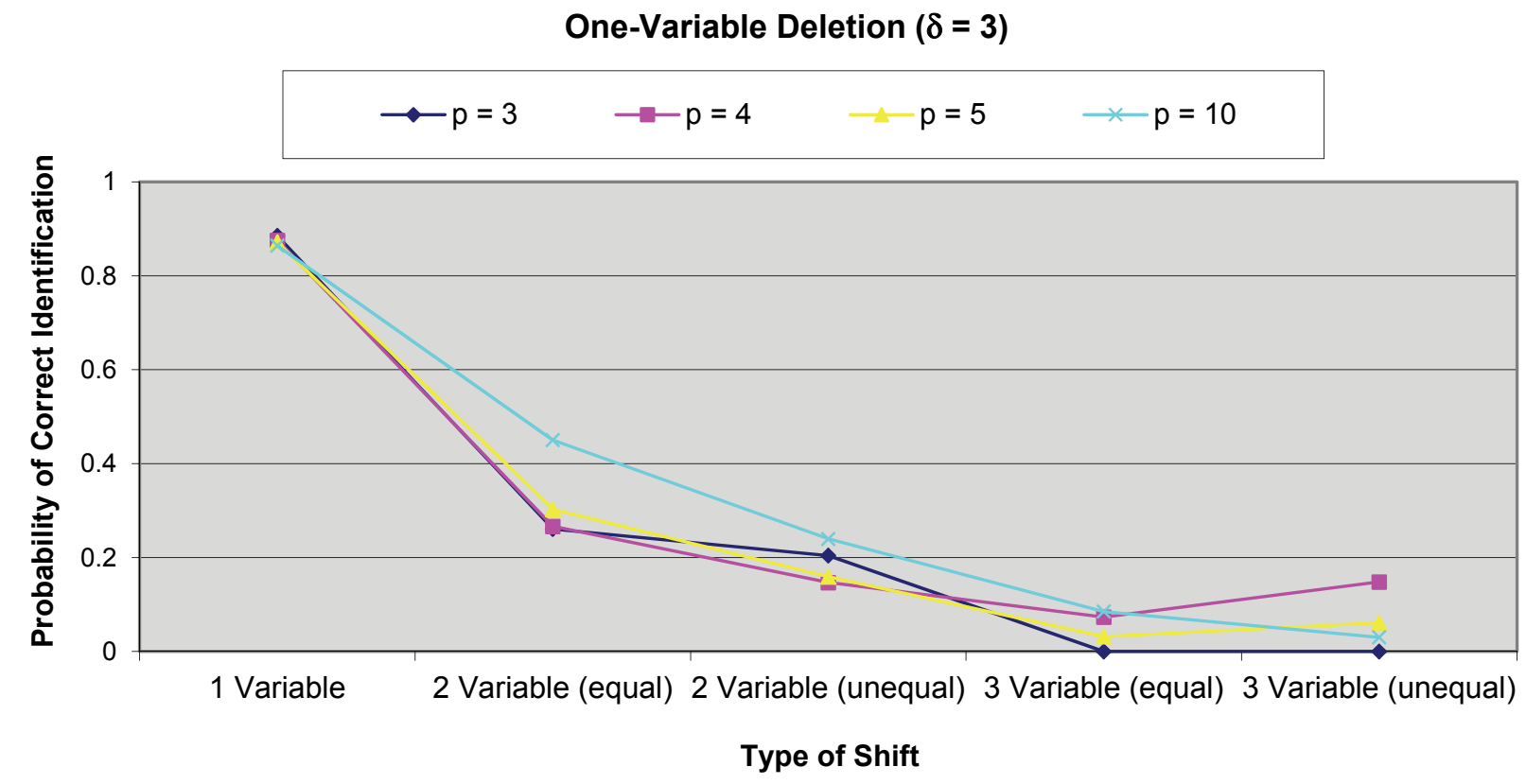


GRAPHICAL EXAMINATION OF VARIABLE DELETION WITHIN THE MEWMA

Figure 11: Success Rate of Two-Variable Deletion when $\delta=1$

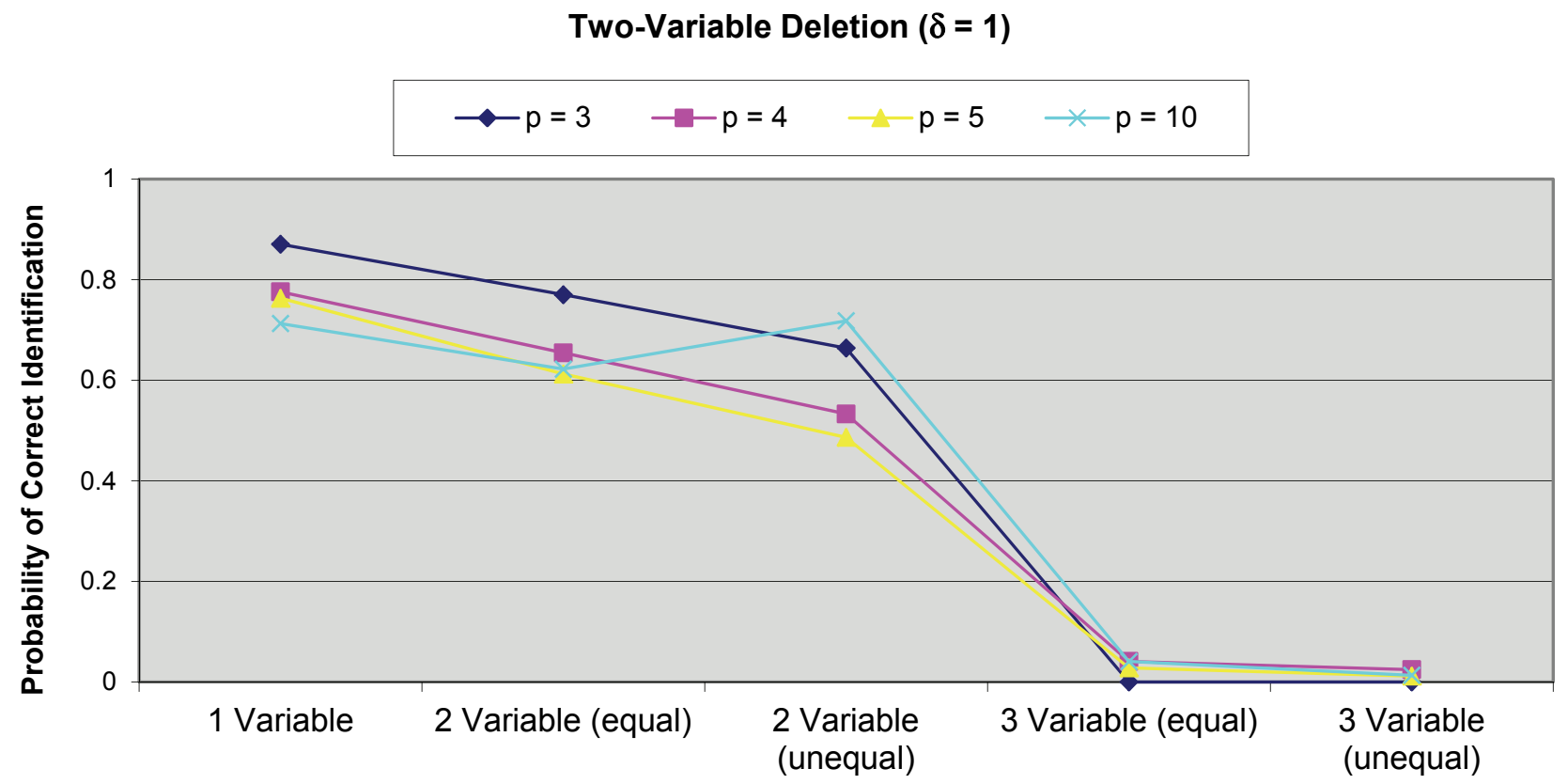

Type of Shift

Figure 12: Success Rate of Two-Variable Deletion when $\delta=3$

Two-Variable Deletion $(\delta=3)$

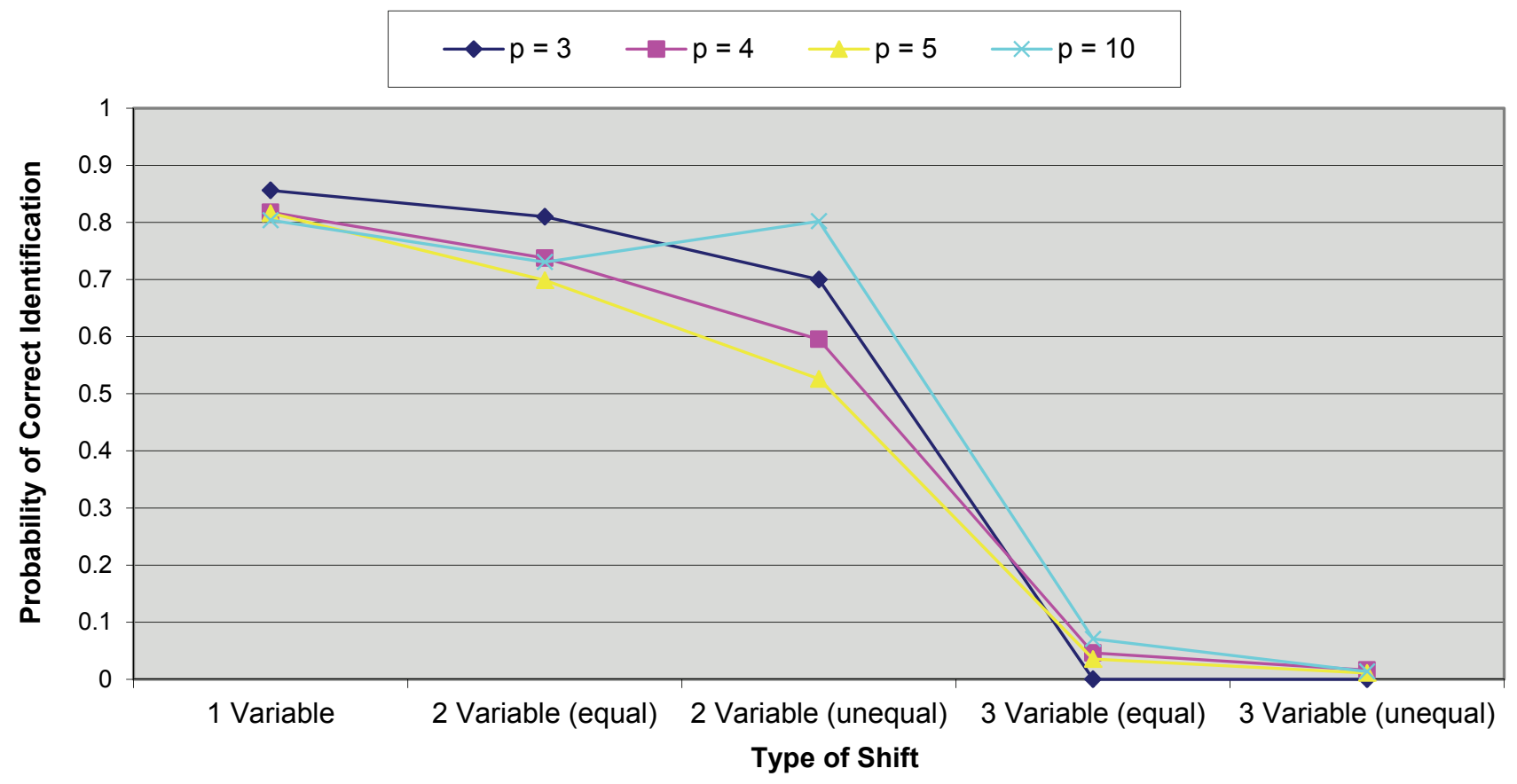




\section{Conclusion}

A general procedure for identifying the variables that contribute to the signal of the MEWMA chart was presented. One-variable deletion correctly identified a one variable shift in 82$89 \%$ of the simulations. Two-variable deletion correctly identified a one variable shift in 71$87 \%$ of the simulations, an equal-sized two variable shift in $61-81 \%$ of the simulations, and an unequal-sized two variable shift in $49-80 \%$ of the simulations.

The success rate decreases rapidly when more variables shift than are removed from the MEWMA statistic. However, examining the reduced MEWMA statistics indicated that the criteria employed herein for a successful identification may not immediately identify the variables that contributed to the signal; however, they did lead to a significantly reduced set of variables to search for the cause of the signal.

This study used only one defined covariance matrix such that the correlation between each pair of variables was 0.5 . It is suspected that an increase in the success rates would be observed if the correlation between the variables is small. In several of the simulations it was noted that, when a variable would shift, it would drag other variables along with it. This in turn clouded the reduced MEWMA statistics making it more difficult to identify the variable that changed using the previously discussed definitions of a success. Further study is required using different covariance matrices.

In addition, the reported success rates assumed if q-variables shifted, then the corresponding definition of a success was used. Further study is required to examine the success rates using various definitions of a success. One suggestion might be that critical values be established to indicate to the operator that a reduced MEWMA statistic is significantly small. Additional simulations should examine the entire distribution of the reduced MEWMA statistics. Critical values could be obtained by examining the distribution of the reduced MEWMA statistics whose variables had not shifted.

Given the power of today's modern computers, variable deletion could be extended to more than two variables being removed from the calculations. Computers could provide a sequential method of analysis in which an operator examines one variable deletion results, then two-variable deletion results, three-variable deletion results, etc. Using such a method, it is anticipated that a reasonable success rate for identifying a q-variable shift using a q-variable deletion would be determined. However, this success rate would likely decrease as more variables are added to the process. Additional research is required in this area.

Using variable deletion in conjunction with the MEWMA control chart should enable a user to employ an efficient multivariate control chart with an effective post hoc analysis. In addition, it provides a helpful and easy to understand graphical solution to the problem of identifying which variable(s) contributed to the signal.

\section{References}

Allen, D. M. (1971). Mean square error of prediction as a criterion for selecting variables. Technometrics, 13, 469-475.

Alt, F. B. (1984). Multivariate quality control. In The encyclopedia of statistical sciences, S. Kotz, N. L. Johnson and C. R. Read, Eds., 110-112. New York, NY: John Wiley.

Belsley, D. A., Kuh, E., \& Welsch, R. E. (1980), Regression diagnostics: Identifying influential data and sources of collinearity. New York, NY: Wiley.

Crossier, R. B. (1988). Multivariate generalization of cumulative sum quality-control schemes. Techonometrics, 30, 291-303.

Hotelling, H. (1947). Multivariate quality control illustrated by the air testing of sample bombsights. In Techniques of statistical analysis, C. Eisenhart, M. W. Hastay, and W. A. Wallis, Eds., 111-184. New York, NY: McGraw-Hill.

Jackson, J. E. (1980). Principal components and factor analysis: Part I-principal components. Journal of Quality Technology, 12, 201-213.

Jackson, J. E. (1985). Multivariate quality control. Communications in Statistics Theory and Methods, 14, 2657-2688.

Jackson, J. E. (1991). A user's guide to principal components. New York, NY: John Wiley \& Sons, Inc. 


\section{GRAPHICAL EXAMINATION OF VARIABLE DELETION WITHIN THE MEWMA}

Lowry, C. A., Woodall, W. H., Champ, C. W. \& Rigon, S. E. (1992). A multivariate exponentially weighted moving average control chart. Technometrics, 34, 46-53.

Lowry, C. A., \& Montgomery, D. C. (1995). Review of multivariate control charts. IIE Transactions, 27, 800-810.

Mason, R. L., Tracy, N. D., \& Young, J. C. (1995). Decomposition of $\mathrm{T}^{2}$ for multivariate control chart interpretation. Journal of Quality Technology, 27, 99-108.

Mason, R. L., Champ, C. W., Tracy, N. D., Wierda, S. J., \& Young, J. C. (1997). Assessment of multivariate process control techniques. Journal of Quality Technology, 29, 140-143.
Pignatiello, J. J., \& Runger, G. C. (1990). Comparison of multivariate CUSUM charts. Journal of Quality Control, 22, 173-186.

Wierda, S. J. (1994). Multivariate statistical process control: Recent results and directions for future research. Statistica Neerlandica, 48, 147-168

Woodall, W. H., \& Montgomery, D. C. (1999). Research issues and ideas in statistical process control. Journal of Quality Technology, 31, 376-386. 